\title{
Sistem Pakar Diagnosa Autisme pada Balita Berbasis Android
}

\author{
Marlika Tosani Pallangan, Vecky C. Poekoel, Alwin M. Sambul \\ Teknik Informatika Universitas Sam Ratulangi Manado \\ Jl. Kampus UNSRAT Bahu, 95115 \\ 110216010@student.unsrat.ac.id, vecky.poekoel@unsrat.ac.id, asambul@unsrat.ac.id
}

\begin{abstract}
Abstrak - Autisme merupakan gangguan perkembangan anak yang sering kali salah dipersepsikan oleh masyarakat. Dengan bantuan perkembangan teknologi, dapat dibuat suatu sistem pakar yang dapat membantu mendiagnosa gangguan autisme pada seorang balita.

Proses untuk mengelola data yang ada dalam penelitian ini adalah menggunakan metode certainty factor. Data yang didapat berupa gejala diagnosa autisme berdasarkan DSM IV TR dan DSM V TR. Metode ini akan mengalikan nilai yang didapat dari pakar dan juga nilai dari pengguna. Penelitian ini menghasilkan sebuah aplikasi sistem pakar untuk mendiagnosa autisme pada balita berbasis android. Pengujian yang digunakan dalam penelitian ini adalah pengujian validasi dan pengujian akurasi. Hasil pengujian validasi yaitu $100 \%$ yang menunjukkan bahwa fungsionalitas sistem berjalan dengan baik. Selain itu, aplikasi ini juga telah diuji secara langsung kepada pakar dan juga kepada pasien yang dinyatakan terkena autisme dan mendapatkan hasil keluaran yang sama dengan hasil diagnosa pakar.
\end{abstract}

Kata kunci : Android, Autisme, Certainty Factor, Sistem Pakar

Abstract - Autism is a child developmental disorder who often misunderstood by the public. Yet, the development of technology enable us to make an expert system to diagnose autism in a toddler.

Certainty factor method is used to process the data in this research. The data obtained is in the form of autism diagnosis symptoms base on DSM IV TR and DSM V $T R$. This method will multiply the value obtained from experts and also the user. This study resulted in an expert system application for diagnosing autism in toddlers based on Android. The test used in this study is a validation testing and accuracy testing. The result of validation testing is $100 \%$ which indicates that the functionality of the system running properly. In addition, this application has also been tested directly to the experts and also the patients and gets the same output with the results of the expert diagnosis.

Keywords : Android, Autism, Certainty Factor, Expert System

\section{PENDAHULUAN}

Teknologi bisa dikatakan sudah menjadi bagian penting dalam kehidupan manusia saat ini. Perkembangan teknologi yang semakin hari semakin maju membuat manusia lebih dimudahkan dalam menjalankan aktivitas kehidupannya. Dengan kata lain, manusia dan teknologi merupakan dua hal yang tidak bisa dipisahkan. Berkembangnya teknologi tentu saja tidak bisa dilepaskan dari peranan manusia yang terus berusaha untuk menciptakan teknologi-teknologi baru. Selain itu, perkembangan ilmu pengetahuan dan teknologi juga merupakan salah satu faktor yang membuat lahirnya teknologi-teknologi baru tersebut. Kebutuhan manusia akan teknologi membuat manusia terus berinovasi untuk mengembangkannya dalam berbagai bidang, salah satunya dalam dunia kesehatan.

Mengkombinasikan kesehatan dan teknologi bukanlah hal yang baru. Sebagai contoh, sudah banyak alat-alat kesehatan yang diciptakan untuk membantu kesehatan manusia. Stetoskop dan termometer merupakan beberapa contoh dari sekian banyak alat kesehatan yang diciptakan sebagai bagian dari perkembangan teknologi dalam dunia kesehatan. Berbicara mengenai kesehatan, sampai saat ini masih banyak kesalahpahaman mengenai anak dengan autisme. Ada yang beranggapan bahwa jika seorang anak memiliki hambatan dalam berinteraksi, artinya dia sudah terdiagnosa autisme, padahal tidak seperti itu. Seseorang dapat dinyatakan terdignosis autisme jika gejalanya telah terlihat lebih dari enam bulan. Panduan untuk mendiagnosa autisme sendiri telah ditetapkan secara internasional yaitu menggunakan panduan Diagnostic and Statitical Manual of Mental Disorder Fourth Edition Text Revision (DSM IV TR) dan juga Diagnostic and Statitical Manual of Mental Disorder Fifth Edition Text Revision (DSM V TR).

Keterbatasan pengetahuan mengenai autisme bisa menjadi salah satu faktor semakin banyaknya anak autis yang terdiagnosa ketika mereka telah berusia di atas 6 tahun. Padahal untuk mendiagnosa autisme sebaiknya dilakukan sebelum usia 6 tahun agar cepat mendapatkan penanganan. Masalah lain yang muncul adalah ketika kurangnya pakar yang bisa memberikan informasi mengenai autisme dengan tepat bagi para orang tua. Salah satu solusi yang dapat ditawarkan untuk mengatasi masalah ini adalah dengan memanfaatkan 
teknologi. Dalam hal ini, sistem pakar bisa menjadi solusi untuk mengatasi masalah tersebut.

Sistem pakar dibuat dengan tujuan untuk mengadopsi pengetahuan satu atau lebih pakar ke dalam komputer agar dapat menyelesaikan masalah seperti yang biasa dilakukan oleh pakar. Karena mengadopsi pengetahuan pakar, maka sistem ini akan bertindak layaknya seorang pakar. Namun, sistem pakar tidak dibuat untuk menggantikan seorang pakar tetapi hanya untuk mengimplementasikan pengetahuan pakar tersebut kepada masyarakat yang masih minim pengetahuan untuk lebih mudah mengetahui hal-hal yang biasanya dilakukan oleh seorang pakar.

Dalam sistem pakar, perhitungan ketidakpastian dapat dilakukan dengan beberapa metode, salah satunya metode certainty factor (CF). Perhitungan ketidakpastian ini diperlukan untuk dapat meyakinkan pasien (pengguna) bahwa hasil diagnosa yang diberikan sistem sudah selayaknya seperti yang diberikan oleh pakar yang dalam hal ini adalah dokter. Metode $\mathrm{CF}$ menggunakan nilai yang akan menggambarkan tingkat keyakinan pakar dalam mendiagnosa autisme.

Berdasarkan latar belakang yang telah diuraikan tersebut, maka penulis bermaksud untuk membuat suatu aplikasi sistem pakar yang dapat membantu untuk mendiagnosa autisme pada balita. Aplikasi ini nantinya diharapkan bukan hanya membantu orang tua yang mungkin mempunyai pertanyaan apakah anaknya terdiagnosa autisme atau tidak, melainkan juga diharapkan bisa membantu tenaga medis dalam pekerjaannya untuk mendiagnosa autisme pada seseorang. Aplikasi ini nantinya akan dibuat berbasis android dan dapat digunakan secara offline sehingga kapanpun dan dimanapun aplikasi ini dapat digunakan oleh masyarakat yang membutuhkan bantuan untuk menjawab pertanyaan mereka tentang tumbuh kembang seorang balita khususnya tentang diagnosa autisme.

\section{A. Autisme}

Autisme adalah cara berpikir yang dikendalikan oleh kebutuhan personal atau diri sendiri, menanggapi dunia berdasarkan penglihatan dan harapan sendiri dan menolak realitas (Kartono, 1989), oleh karena itu, penyandang akan berbuat semaunya sendiri, baik cara berpikir maupun berperilaku (Faisal Yatim, 2003)[1].

\section{B. Sistem Pakar}

Sistem pakar dibuat dengan tujuan untuk dapat menyelesaikan masalah yang sebenarnya hanya dapat diselesaikan oleh ahli. Menurut Giarratano dan Riley (2005), sistem pakar adalah salah satu cabang kecerdasan buatan yang menggunakan pengetahuanpengetahuan khusus yang dimiliki oleh seorang ahli untuk menyelesaikan suatu masalah tertentu [2].

\section{Certainty Factor (Faktor Kepastian)}

Nilai CF merupakan nilai yang didapat dari pengetahuan pakar yang diubah menjadi nilai tertentu. Nilai ini dimulai dengan angka dalam rentang -1 sampai 1. Pemberian nilai berdasarkan pengetahuan pakar ini dapat dilihat pada tabel 1 [3].
Tabel 1. Nilai certainty factor (rule)

\begin{tabular}{lc}
\hline \multicolumn{1}{c}{$\begin{array}{c}\text { Uncertain Term / Kondisi } \\
\text { Tidak Pasti }\end{array}$} & Nilai \\
\hline $\begin{array}{l}\text { Definitely not / Pasti tidak } \\
\text { Almost certainly not / Hampir }\end{array}$ & -1.0 \\
pasti tidak & -0.8 \\
Probably not / Kemungkinan & \\
besar tidak & -0.6 \\
Maybe not / Kemungkinan & -0.4 \\
tidak & -0.2 to 0.2 \\
Unknown / Tidak tahu & 0.4 \\
Maybe / Kemungkinan & 0.6 \\
Probably / Kemungkinan besar & 0.8 \\
Almost certainly / Hampir pasti & 1.0 \\
Definitely / Pasti & \\
\hline
\end{tabular}

Selain nilai dari pakar tersebut, $\mathrm{CF}$ juga menerapkan logika metode pada sesi konsultasi sistem. Di sini yang akan memberikan nilai adalah pengguna. Pengguna akan diberikan pilihan jawaban yang masing-masing memiiliki bobot sebagai berikut :

1) Untuk dua pilihan jawaban :

$\begin{array}{ll}- \text { Tidak } & =0 \\ -\quad \text { Ya } & =1\end{array}$

2) Untuk lima pilihan jawaban :

$$
\begin{array}{lll}
\text { - } & \text { Tidak } & =0 \\
\text { - } & \text { Sedikit yakin }=0.4 & \\
\text { - } & \text { Cukup yakin }=0.6 & \\
\text { - } & \text { Yakin } & =0.8 \\
\text { - } & \text { Sangat yakin }=1 &
\end{array}
$$

$\mathrm{CF}$ sendiri ditunjukkan dengan rumus dasar :

$\mathrm{CF}[\mathrm{H}, \mathrm{E}]=\mathrm{MB}[\mathrm{H}, \mathrm{E}]-\mathrm{MD}[\mathrm{H}, \mathrm{E}\rceil$

Dimana :

- $\mathrm{CF}[\mathrm{H}, \mathrm{E}]=$ Faktor kepastian

- $\mathrm{MB}[\mathrm{H}, \mathrm{E}] \quad$ Ukuran kepercayaan terhadap hipotesa $\mathrm{H}$, jika diberikan evidence $\mathrm{E}$ (antara 0 dan 1)

- $\mathrm{MD}[\mathrm{H}, \mathrm{E}]=$ Ukuran ketidakpercayaan terhadap evidence $\mathrm{H}$, jika diberikan evidence $\mathrm{E}$ (antara 0 dan 1)

Berikut ini adalah deskripsi beberapa kombinasi Certainty Factor terhadap berbagai kondisi :

- Certainty Factor untuk kaidah dengan gejala tunggal (single premis rules) :

$$
\begin{aligned}
\mathrm{CF}(\mathrm{H}, \mathrm{E})= & \mathrm{CF}(\mathrm{E}) * \mathrm{CF}(\text { rule }) \\
& =\mathrm{CF}(\text { pengguna }) * \mathrm{CF}(\text { pakar })
\end{aligned}
$$

- Certainty Factor untuk kaidah dengan kesimpulan yang serupa (similarly concluded rules) :

$$
\mathrm{CF}_{\text {COMBINE }}\left(\mathrm{CF}_{1}, \mathrm{CF}_{2}\right)=\mathrm{CF}_{1}+\mathrm{CF}_{2} *\left(1-\mathrm{CF}_{1}\right)
$$

\section{Android}

Menurut Meier (2009), Android adalah sebuah software stack bersifat open source yang mencakup sistem informasi, middleware dan key application beserta sekumpulan Application Programming Interface (API) untuk merancang sebuah aplikasi mobile dengan menggunakan bahasa pemrograman Java. Android merupakan sistem operasi yang berbasis Linux yang diperuntukkan untuk perangkat seluler layar 
sentuh atau yang biasa disebut dengan touchscreen, seperti ponsel pintar (smartphone) dan tablet [4].

\section{E. Extreme Programming (XP)}

XP merupakan agile methods yang paling popular. XP ditujukan kepada mereka yang melakukan pengembangan sistem secara cepat. XP tidak hanya berfokus pada source code, tetapi meliputi seluruh area pengembangan. XP memiliki empat tahapan dalam pengembangan perangkat lunak, yaitu planning, design, coding, dan testing.

\section{METODOLOGI PENELITIAN}

\section{A. Kerangka Kerja}

Dalam melakukan penelitian, dibutuhkan kerangka kerja agar penelitian dapat berjalan dengan baik. Berikut ini merupakan kerangka kerja yang digunakan dalam penelitian ini.

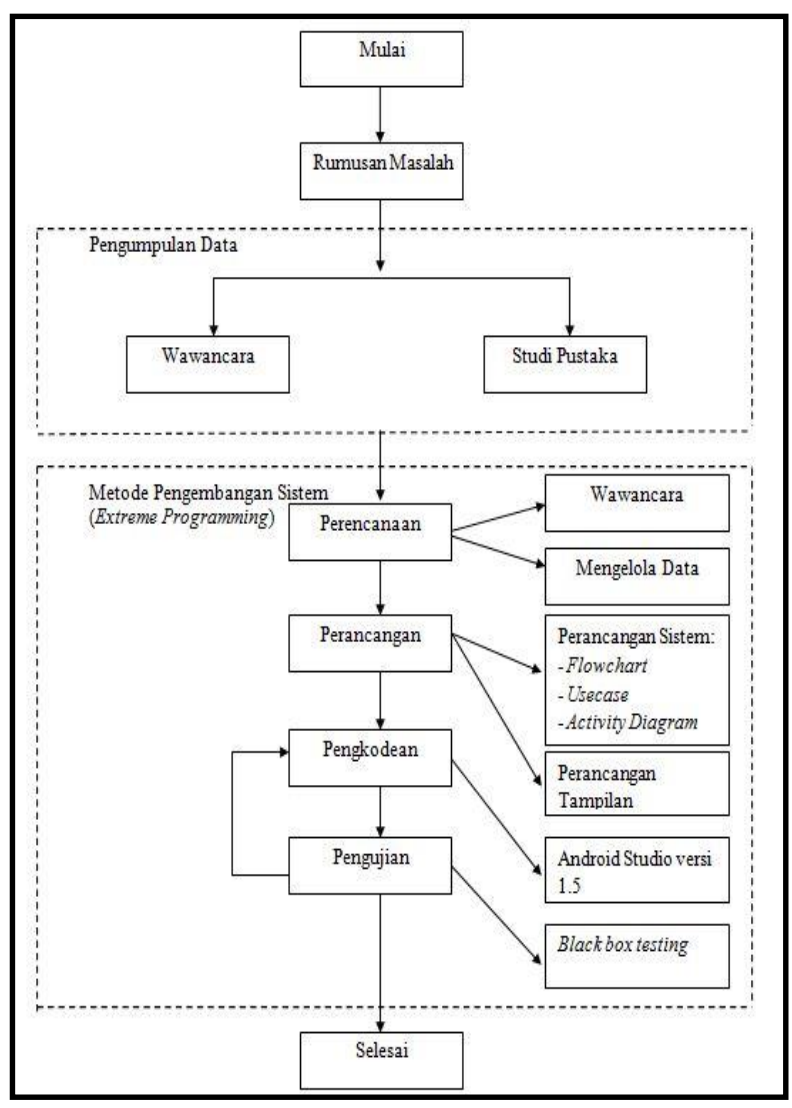

Gambar 1. Kerangka Kerja

\section{B. Metode Pengumpulan Data}

Metode pengumpulan data adalah metode yang digunakan dalam pengumpulan data dan proses penelitian yang diperlukan dalam laporan penelitian. Teknik yang digunakan dalam pengumpulan data, yaitu

1) Studi Kepustakaan

Metode ini digunakan dengan mempelajari data dan rumus-rumus yang didapat dari beberapa literatur serta mengkaji berbagai teori yang berhubungan der $\mathbf{3}$ tema yang dibahas.

2) Wawancara (Interview)
Sebelum proses pengembangan aplikasi, penulis melakukan wawancara dengan pihak terkait. Wawancara ini dilakukan dengan melakukan tanya jawab secara langsung kepada pihak-pihak yang dapat memberikan informasi yang dibutuhkan mengenai permasalahan dan hal-hal yang dibutuhkan dalam proses pembuatan aplikasi. Daftar pertanyaan dan jawaban wawancara dapat dibaca pada Lampiran 1. Wawancara dilakukan dengan beberapa pakar yaitu Hanna Monareh, S.Psi, M.Psi, Psikolog yang merupakan wakil kepala dari Pusat Layanan Autis Provinsi Sulawesi Utara dan Dr. dr. Junita Maja Pertiwi, Sp.S(K) yang merupakan dokter di bagian Pusat Jantung, Pembuluh Darah dan Otak Terpadu RSUP Prof. Dr. R. D. Kandou Manado.

\section{Metode Pengembangan Sistem Extreme Programming}

Metode pengembangan sistem yang penulis gunakan pada penelitian ini adalah metode Extreme Programming $(X P)$. Tahapan-tahapan dari XP yaitu sebagai berikut:

1) Planning (Perencanaan)

Tahap ini dimulai dengan membuat perencanaan untuk mewawancarai pakar-pakar yang dapat memberikan informasi tentang autisme. Inti dari tahap ini adalah mengumpulkan data dan informasi yang akan menjadi basis pengetahuan dari sistem pakar yang akan dibuat. Basis pengetahuan yang digunakan dalam penelitian ini berisi daftar kriteria diagnosa autisme yang digunakan oleh pakar. Basis pengetahuan ini berisi tabel aturan yang berisi hubungan antara jenis gangguan autisme dengan gejala yang menyertainya. Pada saat sesi wawancara, penulis mendapati bahwa ke dua pakar yang memberikan jawaban memiliki pendapat yang berbeda mengenai panduan yang digunakan untuk mendiagnosa autisme. Pakar pertama menggunakan panduan DSM V TR, sedangkan pakar ke dua menggunakan panduan DSM IV TR.

Selama proses wawancara, ke dua pakar memberikan bobot nilai pasti (1) untuk setiap gejala. Karena bobot nilai yang diberikan oleh pakar adalah pasti, maka dalam pengelolaan jawaban yang akan diberikan oleh pengguna hanya menggunakan dua jawaban yaitu tidak yang bernilai 0 dan ya yang bernilai 1.

\section{2) Design (Perancangan)}

Perancangan diperlukan agar memudahkan dalam membaca alur dan membuat sistem. Perancangan suatu sistem bertujuan untuk memberikan gambaran secara umum tentang sistem yang dibuat.

Tahap perancangan ini digambarkan dengan perancangan sistem dan juga perancangan interface (antar muka) dalam pembuatan aplikasi.

\section{- Perancangan Sistem}

Perancangan sistem yang digunakan dalam penulisan skripsi ini yaitu, use case diagram, activity diagram dan flowchart. 


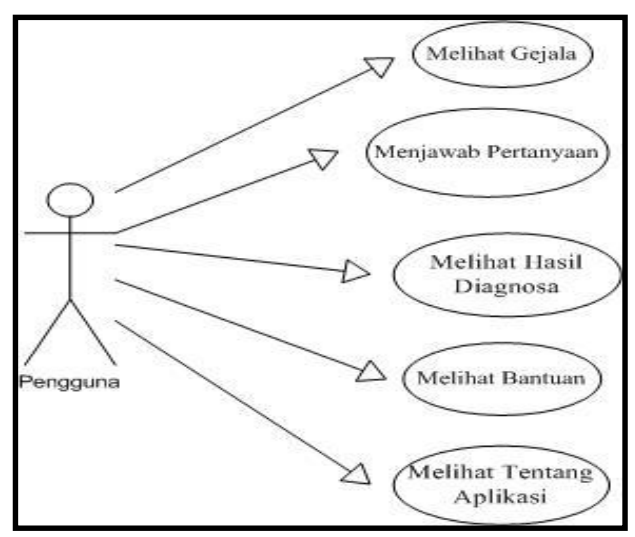

Gambar 2. Use case

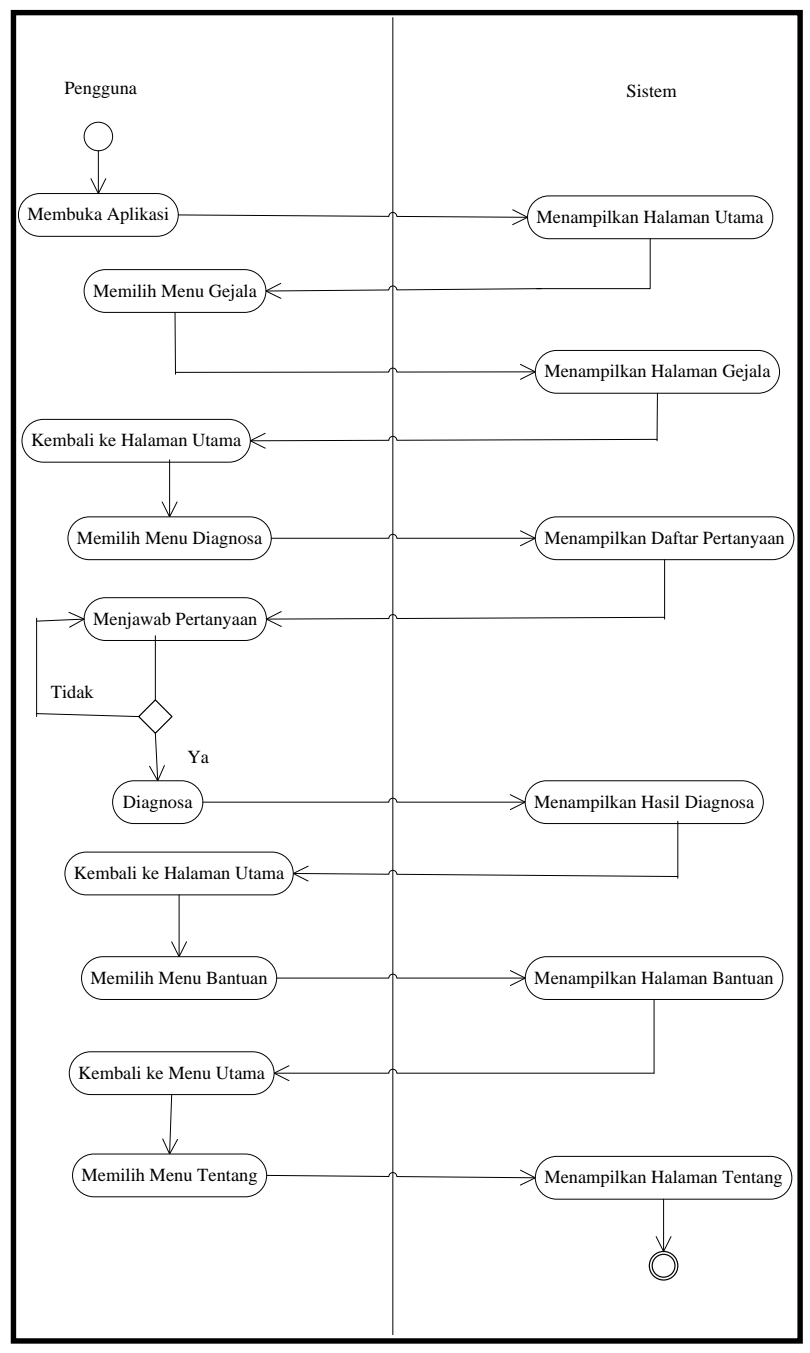

Gambar 3. Activity Diagram

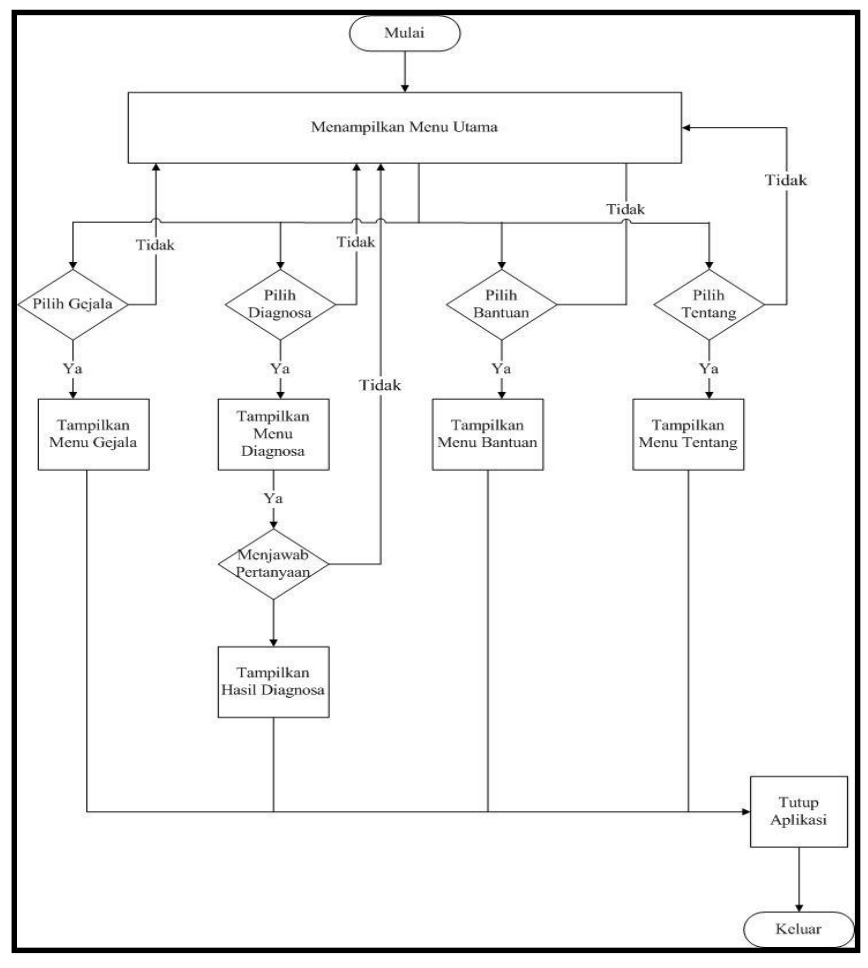

Gambar 4. Flowchart

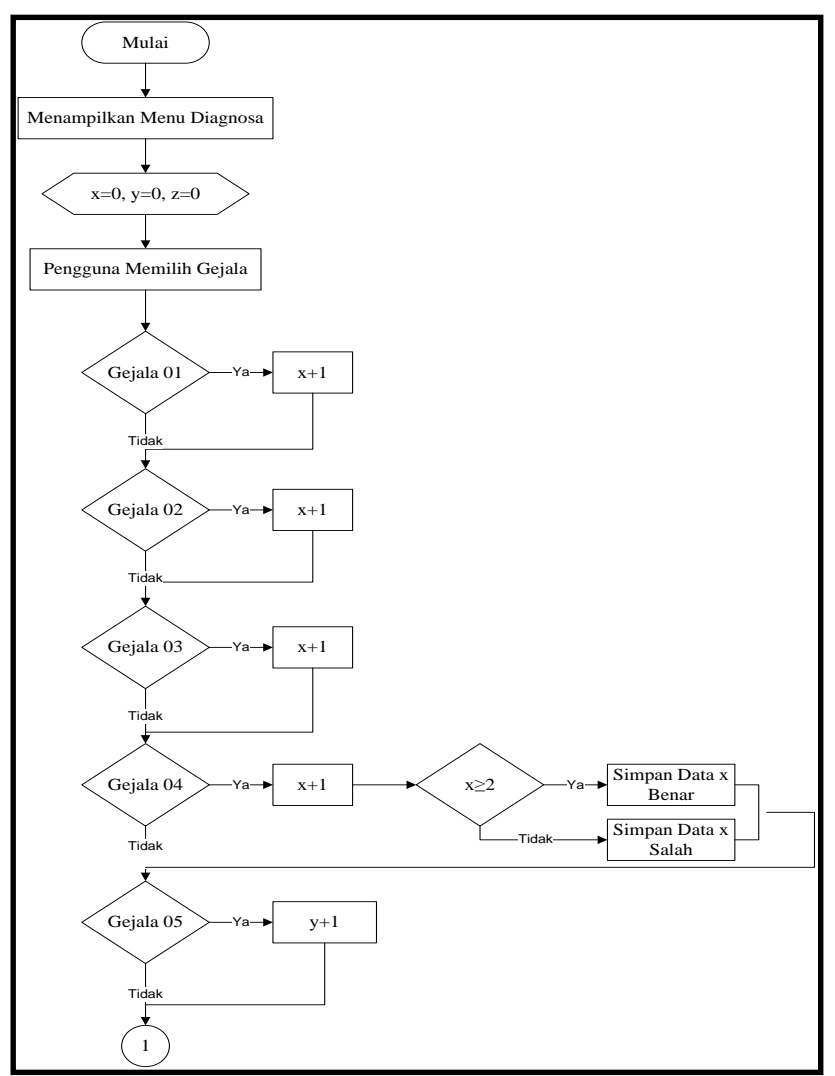



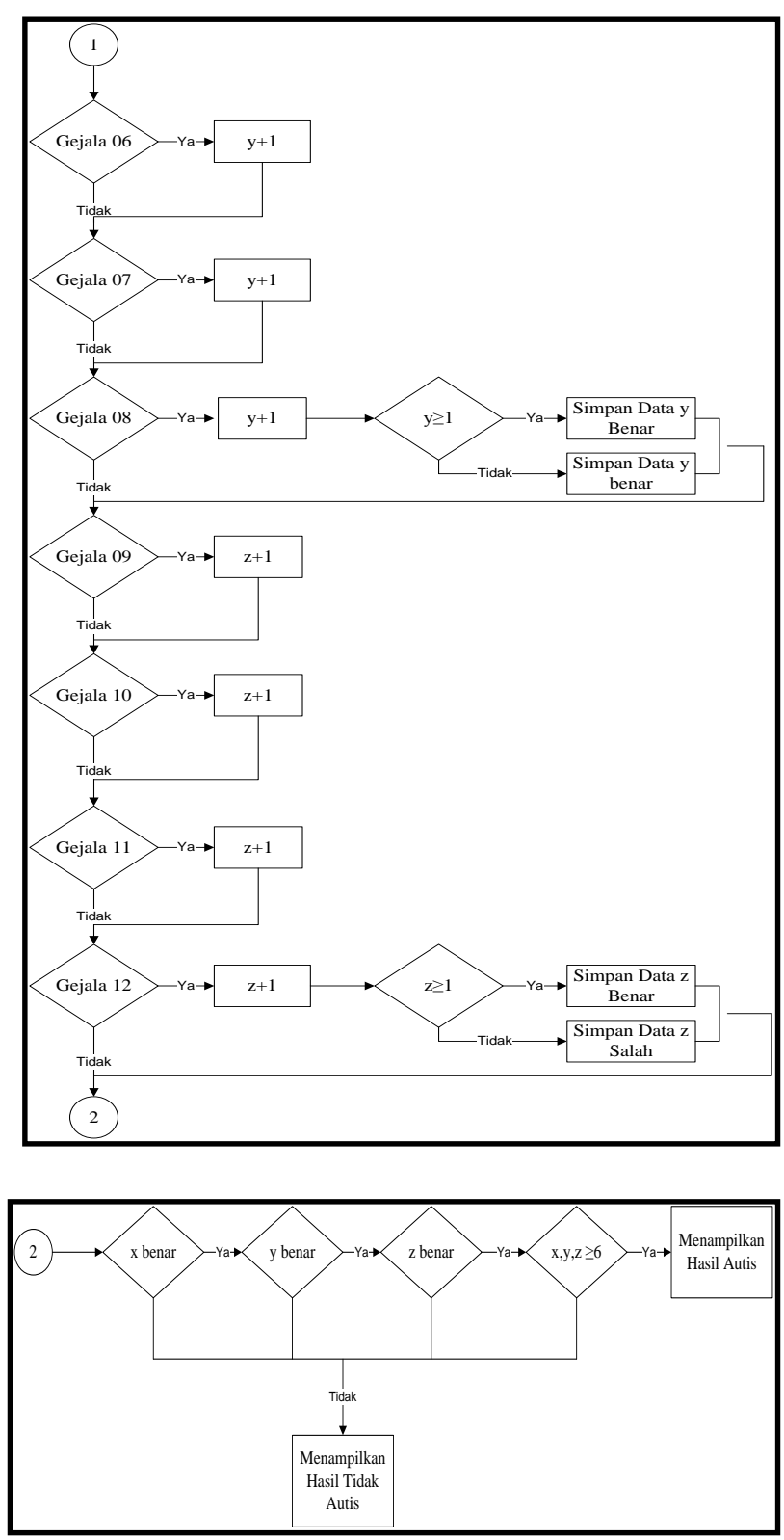

Gambar 5. Flowchart diagnosa autisme DSM IV TR

\section{- Use case Diagram}

Use case diagram menjelaskan aktivitas yang dapat dilakukan oleh pengguna yang berhubungan dengan sistem yang dibuat. Use case diagram pada sistem ini dapat dilihat pada gambar 2.

\section{- Activity Diagram}

Activity diagram ini digunakan untuk menggambarkan aktivitas yang sedang berjalan. Activity diagram sistem ini dapat dilihat pada gambar 3.

\section{- Flowchart (Diagram Alur)}

Flowchart berfungsi untuk menggambarkan proses dalam sistem ini. Gambar 4 merupakan tampilan dari flowchart menu utama. Flowchart ini menjelaskan tentang jalannya menu utama yang dapat digunakan oleh pengguna, mulai dari tampilan awal sampai pilihan-pilihan menu yang ada pada aplikasi.
Sedangkan pada gambar 5 memperlihatkan alur untuk mendiagnosa autisme sesuai panduan yang digunakan.

- Perancangan Interface

Perancangan interface digunakan untuk menggambarkan tampilan antarmuka sebelum aplikasi dibuat. Beberapa rancangan tampilan yang dibuat yaitu, perancangan tampilan splashscreen, tampilan halaman awal dan juga tampilan menumenu yang ada pada aplikasi.

\section{3) Tahap Coding}

Tahap ini merupakan tahap yang paling utama dari model proses extreme programming. Tahap ini bisa berulang kali dilakukan sesuai dengan kebutuhan fungsional yang dapat berubah sewaktuwaktu.

\section{4) Tahap Pengujian Perangkat Lunak}

Pengujian perangkat lunak bertujuan untuk memastikan bahwa aplikasi yang dibuat sesuai dengan tujuan dan tidak ada kesalahan. Pengujian yang dilakukan pada tahap ini adalah pengujian fungsionalitas sistem dengan metode black box dan pengujian akurasi.

\section{HASIL DAN PEMBAHASAN}

\section{A. Interface Sistem}

Gambar 6 merupakan tampilan menu utama yang akan menunjukan tampilan ketika sistem dijalankan. Pada tampilan ini terdapat 4 menu yang dapat diakses oleh pengguna yaitu menu Gejala, menu Diagnosa, menu Bantuan dan menu Tentang. Selanjutnya jika pengguna ingin mengisi daftar gejala untuk mendiagnosa autisme maka pengguna dapat memilih menu Diagnosa dan akan muncul tampilan seperti pada gambar 7. Pengguna akan diberikan pilihan jawaban sesuai dengan gejala yang terlihat pada anak. Jika semua gejala telah diisi maka pengguna dapat melihat hasil diagnosa seperti pada gambar 8 .

\section{B. Pengujian Perangkat Lunak}

Pengujian yang dilakukan pada tahap ini adalah pengujian fungsionalitas sistem dengan metode black box dan pengujian akurasi.

\section{1) Pengujian Black Box}

Dalam penyusunan laporan ini, pengujian yang dilakukan adalah pengujian dengan metode unit testing untuk melihat apakah setiap fungsi pada sistem berjalan seperti yang diharapkan atau tidak. Hasil pengujian dengan unit testing dapat dilihat pada tabel 2 .

\section{2) Pengujian Akurasi}

Peneliti juga melakukan pengujian dengan membandingkan keluaran dari sistem pakar ini dengan hasil diagnosa dari pakar untuk setiap pasien yang dinyatakan terdiagnosa autisme. Hasil dari pengujian sistem ini dapat dilihat pada tabel 3 dan tabel 4 . 


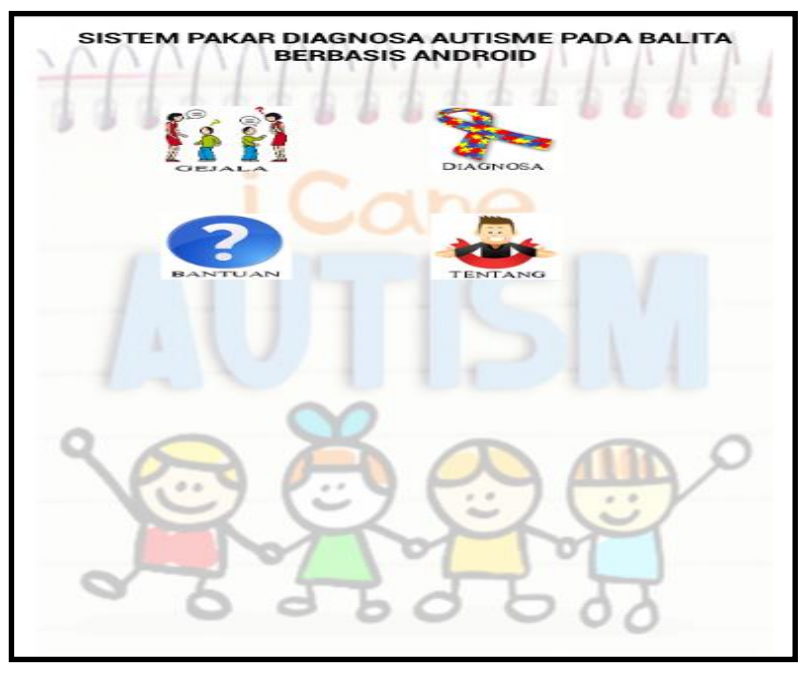

Gambar 6. Tampilan Menu Utama

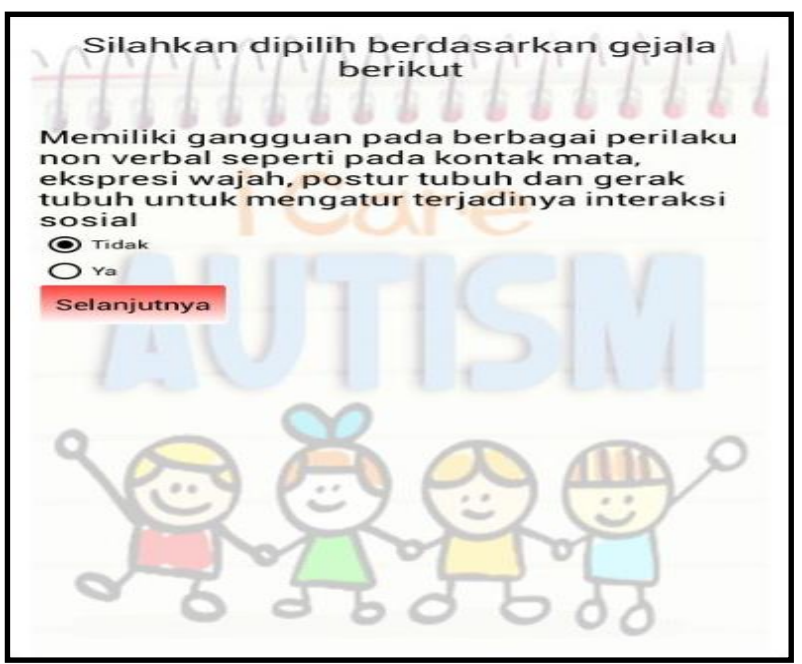

Gambar 7. Tampilan Menu Diagnosa

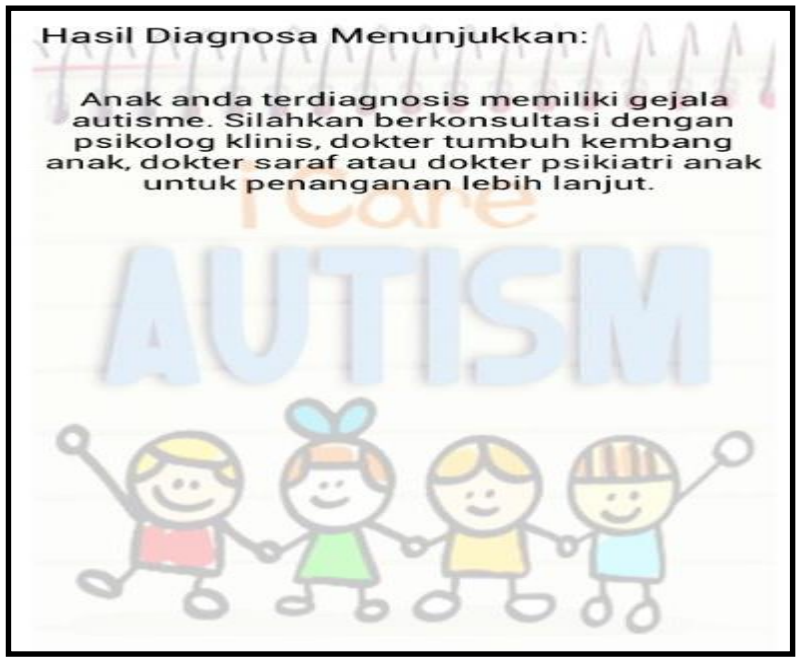

Gambar 8. Tampilan Halaman Hasil
Tabel 2. Pengujian Black Box

\begin{tabular}{|c|c|c|c|}
\hline No & Nama Pengujian & Hasil yang Diharapkan & Hasil \\
\hline 1 & $\begin{array}{l}\text { Fungsi } \\
\text { splashscreen }\end{array}$ & $\begin{array}{l}\text { Sistem dapat melakukan } \\
\text { load aplikasi }\end{array}$ & Valid \\
\hline 2 & $\begin{array}{l}\text { Fungsi menu pada } \\
\text { tampilan awal }\end{array}$ & $\begin{array}{l}\text { Tiap menu dapat } \\
\text { dijalankan tanpa error }\end{array}$ & Valid \\
\hline 3 & Menu gejala & $\begin{array}{lr}\text { Sistem } & \text { mampu } \\
\text { menampilkan } & \text { gejala } \\
\text { autisme } & \end{array}$ & Valid \\
\hline 4 & $\begin{array}{l}\text { Masukan data } \\
\text { gejala }\end{array}$ & $\begin{array}{l}\text { Sistem mampu } \\
\text { menerima masukan data } \\
\text { gejala untuk proses } \\
\text { diagnosa }\end{array}$ & Valid \\
\hline 5 & Proses diagnosa & $\begin{array}{lr}\text { Sistem } & \text { mampu } \\
\text { memproses gejala yang } \\
\text { dimasukan pengguna dan } \\
\text { menampilkan } \\
\text { diagnosa }\end{array}$ & Valid \\
\hline 6 & Menu bantuan & $\begin{array}{l}\text { Sistem mampu } \\
\text { menampilkan informasi } \\
\text { penggunaan aplikasi }\end{array}$ & Valid \\
\hline 7 & Menu tentang & $\begin{array}{l}\text { Sistem mampu } \\
\text { menampilkan informasi } \\
\text { mengenai aplikasi yang } \\
\text { dibuat }\end{array}$ & Valid \\
\hline
\end{tabular}

Tabel 3. Pengujian keluaran sistem sesuai DSM IV TR

\begin{tabular}{cccc}
\hline \multirow{2}{*}{ No } & \multicolumn{2}{c}{ Hasil Diagnosa } & Kr. dr. Junita Maja \\
Pertiwi, Sp.S(K) & Keluaran & Sistem & Set \\
\hline Pasien 1 & Autis & Autis & Sama \\
Pasien 2 & Autis & Autis & Sama \\
Pasien 3 & Autis & Autis & Sama \\
\hline
\end{tabular}

Tabel 4. . Pengujian keluaran sistem sesuai DSM V TR

\begin{tabular}{cccc}
\hline \multirow{2}{*}{ No } & \multicolumn{2}{c}{ Hasil Diagnosa } & Kanna Monareh, S.Psi, \\
& M.Psi, Psikolog & Keluaran & Sistem \\
Pasien 1 & Autis & Autis & Sama \\
Pasien 2 & Autis & Autis & Sama \\
Pasien 3 & Autis & Autis & Sama \\
\hline
\end{tabular}

Tabel 3 dan tabel 4 menunjukkan bahwa aplikasi ini telah diuji secara langsung kepada pakar yaktu Dr. dr. Junita Maja Pertiwi, Sp.S(K) yang menggunakan panduan DSM IV TR dalam mendiagnosa autisme serta Hanna Monareh, S.Psi, M.Psi, Psikolog yang menggunakan panduan DSM V TR dalam mendiagnosa autisme dan mendapatkan hasil yang sesuai dengan apa yang disampaikan oleh pakar.

Berdasarkan hasil dari tabel 3 dan tabel 4, maka dapat dilihat dari tiap data yang diujikan, tidak terdapat hasil keluaran yang berbeda. Berdasarkan hasil tersebut, maka akurasi yang dimiliki sistem pakar untuk mendiagnosa autisme pada balita adalah $100 \%$. 


\section{PENUTUP}

\section{A. Kesimpulan}

Berdasarkan pembahasan pada bab-bab sebelumnya, maka dapat ditarik kesimpulan sebagai berikut:

1) Sistem pakar untuk membantu mendiagnosa autisme pada balita berhasil dibuat dengan menggunakan metode certainty factor dalam pengelolaan setiap gejala. Aplikasi ini mengolah masukan yang diberikan oleh pengguna berdasarkan gejala yang didapat dari pakar dan juga panduan diagnosa autisme yang digunakan oleh pakar.

2) Berdasarkan hasil pengujian semua fungsi pada aplikasi ini mendapatkan hasil yang valid. Selain itu, aplikasi juga telah diuji secara langsung ke dokter saraf dan psikolog klinis dan mendapatkan hasil yang sesuai dengan panduan yang digunakan pakar. Aplikasi ini juga telah diujikan secara langsung kepada pasien yang didiagnosa autisme dan didapati bahwa keluaran dari aplikasi ini sama dengan diagnosa dari pakar. Dengan adanya aplikasi ini, maka pengguna dapat melakukan diagnosa terlebih dahulu sebelum mengunjungi dokter.

3) Aplikasi ini memiliki ukuran yang kecil tidak lebih dari $7 \mathrm{MB}$ sehingga tidak memerlukan ruang penyimpanan yang besar untuk menginstal aplikasi ini.

\section{B. Saran}

Dari penelitian ini, masih banyak kemungkinan untuk mengembangkan aplikasi yang lebih baik lagi. Beberapa saran yang dapat diberikan untuk pengembangan aplikasi diantaranya :

1) Sistem pakar yang dihasilkan baru sebatas memberikan hasil diagnosa secara umum dan belum memberikan hasil yang lebih spesifik seperti memberikan saran terapi untuk penanganan autisme.

2) Penelitian lebih lanjut diharapkan dapat membuat sistem yang mampu mendiagnosa gangguan perkembangan anak yang lain yang termasuk dalam ASD (Autistm Spectrum Disorder).

\section{DAFTAR REFERENSI}

[1] F. Yatim. Autisme (Suatu Gangguan Jiwa Pada Anak-anak). Pustaka Populer Obor. Jakarta.2003

[2] Giarratano dan Riley. Expert System: Principles and Programming edisi 3. PWS Publishing Company. USA.2005

[3] G. Virginia. Implementasi Sistem Pakar Untuk Mendiagnosa Penyakit Dengan Gejala Demam Menggunakan Metode Certainty Factor. Teknik Informatika Universitas Kristen Duta Wacana. Yogyakarta. 2010

[4] N. Safaat. ANDROID Pemrograman Aplikasi Mobile Smartphone dan Tablet PC Berbasis Android. Informatika. Bandung. 2012

\section{SEKILAS TENTANG PENULIS}

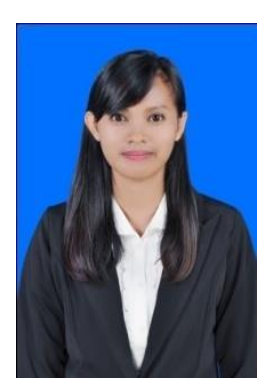

Marlika Tosani Pallangan, lahir di Sorong, Papua Barat pada tanggal 12 Maret 1994. Anak ke-1 dari 3 bersaudara dengan pendidikan Sekolah Dasar YPK IV Pniel Sorong. Penulis lalu melanjutkan ke Sekolah Menengah Pertama Negeri 9 Sorong. Lalu ke Sekolah Menengah Atas Negeri 1 Sorong. Penulis kemudian melanjutkan studi di Fakultas Teknik, Jurusan Elektro, Program Studi Informatika, Universitas Sam Ratulangi Manado. Pada Tahun 2015 bulan Oktober, penulis membuat Skripsi demi memenuhi syarat Sarjana (S1) dengan penelitian berjudul Sistem Pakar Diagnosa Autisme pada Balita Berbasis Android yang dibimbing oleh dua dosen pembimbing yaitu Dr. Eng Vecky Poekoel, ST., MT dan Alwin M. Sambul, ST., M.Eng., PhD. Penulis dinyatakan lulus dari Program Studi Teknik Informatika Jurusan Elektro Universitas Sam Ratulangi Manado pada tanggal 26 Januari 2017. 